\title{
The Core Value of Modern Mass Transit Systems
}

\author{
Ching-Lung LIA0* \\ Director, Railway Technology Research Center, National Taiwan University
}

*Corresponding author: Ching-Lung LIAO, Director, Railway Technology Research Center, National Taiwan University, Taiwan.

Received Date: February 23, 2020

Published Date: March 03, 2020

\begin{abstract}
The mass transit system is a behemoth in a metropolis. It requires a lot of investment, human and material resources, but there is no way to try samples. Once the construction of the hardware facilities is completed, it will be difficult to modify them in the future. Rarely two lines are the same. It is not possible to fully replicate the specifications and meet the needs of the line. Therefore, the core value base strategy is very important. As long as the core values are correct, the system established will meet the needs of local society and industry.
\end{abstract}

\section{Opinion}

The core value of the modern mass transit system should be able to provide services to citizens withouta driver's license and meet the needs of commuters every day. In other words, the most important thing is to make these two types of citizens happy to use the mass transit system. Before constructing a new mass transit system, you should first study what design can effectively provide these two types of passenger services. When operating, pay attention to the opinions or reflections of these two types of passengers at any time, as long as you feel inconvenient for certain facilities and operations When this happens, the operating organization should make every effort to improve and adjust. Problems for people without driver license Citizens without driver licenses are mostly seniors, minors, and people with reduced mobility for example, people with baby strollers, and large luggage, and in wheelchairs and crutches. When they go shopping, visit friends or go to the hospital, they often need a ride from someone who has a driver license. It is a great burden for people who need to work at the same time. If the mass transit system is easily accessible to people with reduced mobility, it will also significantly reduce the social problems associated with rapid population aging.

\section{Barrier Free Space}

People with reduced mobility are usually slow or inconvenient, so their activity space should be barrier-free. The facilities or equipment should be set up in a way that is a little different from non- disabled human behavior. Usually, escalators or ramps are the main lifting equipment. It will guide many passengers with reduced mobility or those with heavy luggage willing to use mass transit systems. The barrier-free space should be set at the same standard at all stations or where passengers are going. As long as it gets stuck in some places, people with reduced mobility will have less willingness to use it. Escalators or gentle slopes not only make the line move smoothly and increase the speed, but they also serve others. Although the elevator is slow and has limited space, it should also be close to the main moving line so that people with reduced mobility can use it. There are many details needed to be considered in a barrier-free facility. Smooth pathways are the first priority. For example: no steps, leveled grounds, and the door gaps and expansion joints must be smooth. The design of such a facility should not be obstructed by moving lines. The walking distance between different train lines should not be too far.

\section{Hope for Commuter}

The hope for commuters is straight forward, that is, to arrive at the office or school in the shortest time without feeling tired and start work immediately.

\section{Shortest Travel Time}

The commuting behavior is relatively fixed, so the flow distribution of the commuter population in the city should be 
investigated first. Furthermore, the network should be planned so that the few times the commute requires transfers, the transfer time is shorter. Taipei MRT has an excellent interchange design with two different lines in the same location (Figure 1). Both lines allow two trains to reach the platform at the same time during peak hours and then stop for about 40 to 50 seconds. It gives people time to move quickly without having to wait for the next train, which is very helpful for commuters. However, the distances between the stations that intersect the two routes are different. If there is a need to have two trains to appear on the platform at the same time, they must pay special attention to the train control (Figure 1).

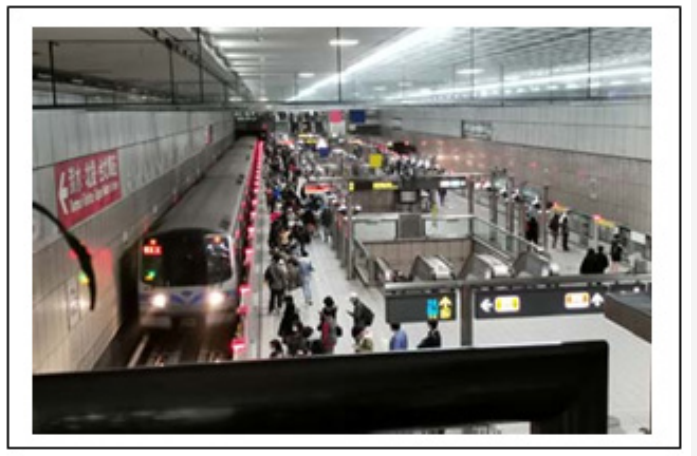

Figure 1: Two trains coming in at the same time.

\section{Stable Transit System}

Most human behavior is controlled by habit. After habit formation, we can still do it subconsciously even if we don't pay attention in the process. This is a powerful survival weapon formed by humans for millions of years. If the mass transit system is stable and consistent, commuters can easily reach their destination consciously. This riding process eventually can become a habit. It is important for people to stay energized even if they commute to work every day, and to be prepared to respond to everyday challenges quickly. The key to making commuters habitually use the mass transit system is the function of train operation. The passenger experience must always be the same and predictable. From the time the train stops on the platform, all the performance of the train must be anticipated: when the door closes, when the train starts, how much speed it accelerates, how much lateral force it withstands and it vibrates and squeaks when the train turns etc.. If the train commuter takes enough rides, the human body will naturally take the necessary countermeasures.
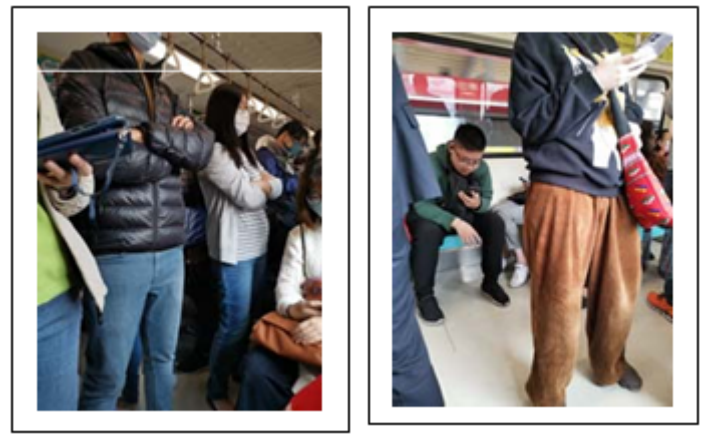

Figure 2: Passenger performance in Taipei MRT carriages.

Figure 2 is a phenomenon that often occurs in the Taipei MRT system. When the train is moving at full speed, many standing passengers are still using their mobile phones without holding the handles. Not that they don't care about safety, but that the body's natural subconscious response can also make passengers safe. The premise is that the train system must always be stable. When crowded, the acceleration curve must be the same as that of an empty car. In other words, the traction of the train must be controlled using a closed loop. Therefore, mass transit systems for commuting will be more complex and expensive.

\section{Conclusion}

In summary, the modern mass transit system should be expanded as much as possible for all citizens and reduce the impact on environmental changes for commuters. If people who don't have a driver's license and commute daily like to take the mass transit system, the city can transfer into a healthy environment with happy working citizens. However, in practice, there are some limits to the improvement of the mass transit system. Therefore, in addition to adjusting the system, it is also necessary to adjust the mentality 
of the citizens. The positive and optimistic prospect of urban development prospect is the main criteria for a happy city full of promise.

\section{Acknowledgment}

None.

\section{Conflict of Interest}

No conflict of interest. 